\title{
Design for collective intelligence: Pop-up communities in MOOCs
}

\author{
Muriel Garreta-Domingo* \\ ICT Department, Universitat Pompeu Fabra, Barcelona, Spain \\ Roc Boronat 138, 08018 Barcelona, Spain \\ (+34) 34935421428 \\ murielgd@gmail.com \\ Peter B. Sloep \\ The Welten Institute of the Open University of the Netherlands, Heerlen, The Netherlands \\ Valkenburgerweg 167, 6401 DL Heerlen, Netherlands \\ (+31) 455672629 \\ peter.sloep@ou.nl \\ Davinia Hérnandez-Leo \\ ICT Department, Universitat Pompeu Fabra, Barcelona, Spain \\ Roc Boronat 138, 08018 Barcelona, Spain \\ (+34) 34935421428 \\ davinia.hernandez@upf.edu \\ Yishay Mor \\ The centre for innovation and excellence in teaching, Levinsky college of education, Tel Aviv, Israel \\ 15 Shoshana Persits St., Tel Aviv 61481, Israel \\ (+972) 36901690 \\ yishaym@gmail.com
}

\begin{abstract}
Many current authors point towards the heightening of networked individualism and how this affects community creation and engagement. This trend poses strong challenges to the potential beneficial effects of collective intelligence. Education is one of the realms that can strongly suffer from this globalized individualism. Learning is deeply enhanced by social interactions and losing this social dimension will have long-lasting effects in future generations. Networked learning is also a by-product of our societal context, but not per se individual. Our paper presents a case - the HANDSON Massive Open Online Course (MOOC) - in which a purposely designed learning environment fosters the emergence of a kind of collective intelligence which, by the learners own accord, brings about a heightened sense of community. The MOOC's design managed to enable individual learning paces without sacrificing the social dimension. Thus, we argue that when learning together intentionally and informally in networked online environments, small and temporary communities (pop-up communities we call them) will form. This nascent sense of community is a first step that will ultimately contribute to the common good.
\end{abstract}

Keywords collective intelligence, learning design, networked learning, MOOCs, networked individualism, pop-up community 


\section{Introduction}

In this day and age, as individuals we sit in the middle of a networked world, with massive amounts of information at keyboard's length, with vast numbers of individual people accessible through email, chat, social media, video conferencing and mobile phones, with few or no boundaries of time and space. Such a world differs in obvious ways from the pre-Internet world of only 25 years ago. As a consequence thereof, people conceive of social relations differently. Where in the past geographical space was decisive in one's choice of whom to connect with, at present what matters most is who these people are, what they do and how they can contribute to achieving one's own goals. In their book Networked: The New Social Operating System Lee Rainie and Barry Wellman (2012) call this new conception of sociality networked individualism. According to them, it captures the particular way in which people socialize who have embraced the triple revolutions of adopting social networks, Internet, and mobile devices as integral parts of their lives.

Does this kind of individualism leave room for a genuine sense of community, one may wonder, for a willingness to collaborate and together achieve things that individuals are incapable of achieving alone? Robert Putnam (2000), using a wealth of American data, argues that we have become increasingly disconnected from family, friends, neighbours, indeed from our democratic structures. Our stock of social capital, he argues, has plummeted, tearing apart our (offline) communities and impoverishing our lives (see also O'Hallam 2016). So, networked individualism may be an apt description of our present-day world, there is an urgent need to mitigate its ill effects. We do need to find ways to maintain the benefits that cyberspace, the Internet and social media afford us without doing away with our civil and civic society. In communication theory, for example, there is a worry that our discussions, when conducted online, have become more shallow and less aware of elementary social norms (ibid.). Likewise, in education there is a consensus that learning is deeply enhanced by social interactions (e.g. Dillenbourg 1999), but will they remain as beneficial when educational interactions go online? Indeed, social interactions, notably educational ones, should be constitutive of the collective intelligence that is to serve our future generations.

For sure, education is making ever more inroads into the networked world, in the context of non-formal learning (Carvalho and Goodyear 2014; Dron and Anderson 2014), but increasingly also in the context of formal education (Bates 2015; Carvalho and Goodyear 2014). This is to be welcomed, as it allows learners and teachers to seize unprecedented opportunities (Dalziel 2016; Laurillard 2012). Resources for learning may be searched for, found and read through, the constraints imposed by place and time may be overcome; and perhaps most importantly, connections with peer learners may be forged for learning together. Massive Open Online Courses (MOOCs) provide a particularly apt example of this change towards networked learning (Haythornthwaite 2011; Siemens and Conole 2011; Sloep and Berlanga 2011). Being hailed as a revolution in education (Daniel 2012), MOOCs embrace Internet technology and approach learners individually, without burdening them with a curriculum, class or peer group.

Thus, online learning can be social but not necessarily taking advantage of collective intelligence for the benefit of mutual learning. MOOCs are a good example of this. Most massive open online courses - 
especially those designed as xMOOCs (Bates 2015) - have focused on the individual learner as a "networked individual". With this, we do not mean that social interactions among its students can not happen; but that the design of the course was not designed to foster the social dimension of learning. We refer here to the principle of harnessing the collective intelligence of networks (Ilon 2012).

In fact, to make this principle actionable, many paths and mechanisms can be taken and implemented. However, they should all be able to answer the following questions: In a given network - say a collection of individuals bound by a shared common interest, however generic that may be - how can the joint intelligences of the network members be tapped into; how can they be orchestrated to engage in productive dialogue; how can this dialogue contribute to the benefit of the network as a whole: the common good (as opposed to the benefits of the individuals that participate in it only); and how can networked individuals be convinced that contributing to this common good is valuable, even if they may not see the immediate benefits to themselves thereof? These are too many questions, and too complex at that, to address in a single paper. Here, we will rest content with illustrating, in the context of education and in particular networked learning, how a properly designed learning environment fosters the emergence of a kind of collective intelligence which, by the participants own accord, brings about a heightened sense of community. We will then argue that this sense of community is the basis upon which common goods can be built.

In the present context, we will focus on networked forms of learning only. We do so as they embrace the online world in ways similar to networked individualism. Networked learning should therefore be liable to the same threats and dangers that networked individualism is exposed to. We will be looking at a particular instance of networked learning, a MOOC-based course. Networked individualism predicts that people will only engage in social interactions if they individually profit from this. At face value, this does seem to be the case in our study. However, when looking more closely, participants admit that they did experience the emergence of a sense of community. We will discuss how, in our view, this shift in attitude came about in the present network. We will argue that when learning together intentionally and informally in networked online environments, small and temporary communities (pop-up communities we call them) will form. In the short run they only serve the immediate learning needs of their participants. However, through them weak links are explored and potentially longer-lasting relationships are forged (Haythornthwaite 2012). These pop-up communities, we argue, represent a kind of collective intelligence. In the short term they may seem to serve the private good of its participants only. However, if weak links solidify into stronger ones, pop-up communities give rise to genuine communities, in which contributing to the common good is the norm. Thus, we see how MOOC platforms are sociotechnological systems that have the potential to promote collective intelligence for the common good of mutually learning together as a network. However, the design of the environment that can facilitate this presents challenges. The paper discusses the challenge of addressing the social dimension of learning to cater for an open and large group formed by a multilingual audience. The aim is twofold: facilitate individual learning paces while leveraging the power of peers, and move from a centrally-facilitated to a decentralised, autonomous community.

The rest of this paper is organised as follows. First, we will discuss our approach to designing networkedlearning MOOCs for continuous professional development (Section 2). Then in Section 3 we will look at the results of two studies we carried out, in subsequent editions of one and the same MOOC 
(HANDSON) and at the results of a facilitator survey. Finally, Section 4 is devoted to drawing conclusions and discussing their significance with respect to our design challenge.

\section{The Case of a MOOC for Teacher Training}

\subsection{The design of the MOOC}

The HANDSON project (handsonict.eu), funded by the European Commission, aimed at providing inservice teachers with the necessary skills to include ICT tools in their teaching. Although ICT has been around for some time, its inclusion in the classrooms and lecture halls still leaves to be desired (OECD 2015). To accomplish this, the project designed and subsequently developed a MOOC that guides teachers through a lesson design process. The design of the MOOC makes use of Carvalho and Goodyear's ACAD framework (2014). ACAD discerns three design components. The epistemic design concerns the tasks learners carry out in order to acquire new knowledge. The set and social designs concern the 'environment' in which the learner operates, the resources, tools, procedures, etc. that they make use of (set design) and their peers, teacher, tutors, etc. with whom they interact (social design). The very first design ideas for the MOOC were piloted with experts only (Stoyanov et al. 2014). Informed by their comments, two different editions of the MOOC were run, the second edition profiting from insights gained during the first one (Garreta-Domingo and Colas 2015). Though sharing many aspects, they differed in a few key ones, mostly in their social design. We'll describe commonalities first, later to discuss differences.

The epistemic design for the HANDSON MOOC emphasized a hands-on, project-based approach. It required participants to act as learning designers themselves (Garreta-Domingo et al. 2015a) and design an ICT-based learning activity ready to use in their own lessons. During the five weeks of the MOOC, participants carried out a series of design tasks, working their way through five subsequent, week-long design phases: initiate, investigate, inspire and ideate, prototype, and evaluate and reflect. This phased course outline is an adaptation of the Learning Design Studio approach by Mor and Mogilevsky (2013).

The set design comprised several tools and environments:

- $\quad$ an open source virtual (online) learning environment (VLE) as the course platform

- $\quad$ an Integrated Learning Design Environment (ILDE, ilde.upf.edu/about) (Hernández-Leo et al. 2014)

- Google Hangouts for the weekly convergence sessions, and

- various web 2.0 tools for prototyping purposes.

The social design concerns the way the facilitators interacted with the participants and the participants with each other. Going from the first to the second edition, facilitator involvement was made more intense. But perhaps even more importantly, while in the first edition all course business was conducted in English only, in the second edition the materials were still made available in English, but seven language groups were established in which participants could interact with each other and their facilitators in the language of their choice, often their native language (Colas, Sloep and Garreta-Domingo 2016). Table 1 summarizes all changes made between the two editions. 
Table 1

Summary of design differences between the two editions of the HANDSON MOOC

\begin{tabular}{|l|l|l|}
\hline & \multicolumn{1}{|c|}{ First Edition } & \multicolumn{1}{c|}{ Second Edition } \\
\hline Epistemic design & $\begin{array}{l}\text { 20 tasks set to participants (in } \\
\text { English) } \\
\text { Two tasks related to evaluation } \\
\text { protocols }\end{array}$ & $\begin{array}{l}\text { 23 tasks set to participants (in English) } \\
\text { Peer-mentoring tasks part of the course; } \\
\text { one task for evaluation }\end{array}$ \\
\hline Set design & Course VLE: Moodle & Course VLE: Canvas \\
\hline Social design & $\begin{array}{l}\text { English only peer-feedback, public } \\
\text { and promoted by facilitators. } \\
\text { On Moodle and ILDE }\end{array}$ & $\begin{array}{l}\text { One peer-review task per week with } \\
\text { rubrics, private to peers involved in task. } \\
\text { Feedback was given in one of the seven } \\
\text { languages supported. } \\
\text { On Canvas }\end{array}$ \\
\hline
\end{tabular}

The first edition of the HANDSON MOOC was offered from May 19th to June 20th of 2014. It counted 743 participants from 42 countries, the largest group coming from Greece (58\% of initial participants). The MOOC featured three paid facilitators and one technical support person. 68 (9.1\%) of the participants finished the MOOC, that is, obtained the final badge of "designers".

The second edition ran a few months later, from October 27th to November 28th of 2014. The number of participants registered more than doubled (from 734 to 1515). It had two paid facilitators, 15 active volunteer facilitators, and one technical support person. 92 (6.7\%) of participants completed this second edition, and obtained the designer's badge.

To analyse the fates of the communities in both editions of the HANDSON MOOC, we tapped into the following sources of data:

1. activity report from Moodle (first edition of the MOOC only)

2. activity reports from ILDE, with a focus on the comments that facilitators and participants made with respect to each other's designs

3. run-time surveys, which were sent to the participants at the beginning and end of both editions

4. final survey, which was sent to the 15 active facilitators at the end of the HANDSON project.

. 2.1 The design of the MOOC

\subsection{Collective participant behaviour in the HANDSON MOOC}

\section{First edition}

In terms of social design, the facilitators of the first edition engaged participants by kicking-off all communications, clarifying doubts, commenting on participant's designs for learning with ICT, and in general promoting the interaction among participants. The social network graphs in Figure 1 show how 
the interaction in the forums developed over course time, that is, how the number of messages from participants (orange nodes) increased and the number of messages from facilitators (blue nodes) decreased (Garreta-Domingo et al 2015b). This suggests that thanks to the course's social design the participants increasingly adopted their role of peers. Table 2 reinforces this picture, showing how the number of participant messages almost monotonously grew from 3.04 to 5.35 (final column).

Interestingly, this trend is not reflected in the number of messages per discussion thread (one but final column), fluctuating between 13.8 (week 2) and 2.8 (week 5). However, this does not gainsay our earlier finding as thread numbers are likely to reflect the number and complexity of facilitator-set tasks. So, we may conclude that, as the course advanced, the participants took a more prominent role in the communication and interaction in the forums, suggesting forms of community formation were taking place, as intended by the social design.

\section{Figure 1}

Social network graphs depicting interactions in the weekly Moodle forums for the first edition of the HANDSON MOOC; ordered from week 1 to 5.

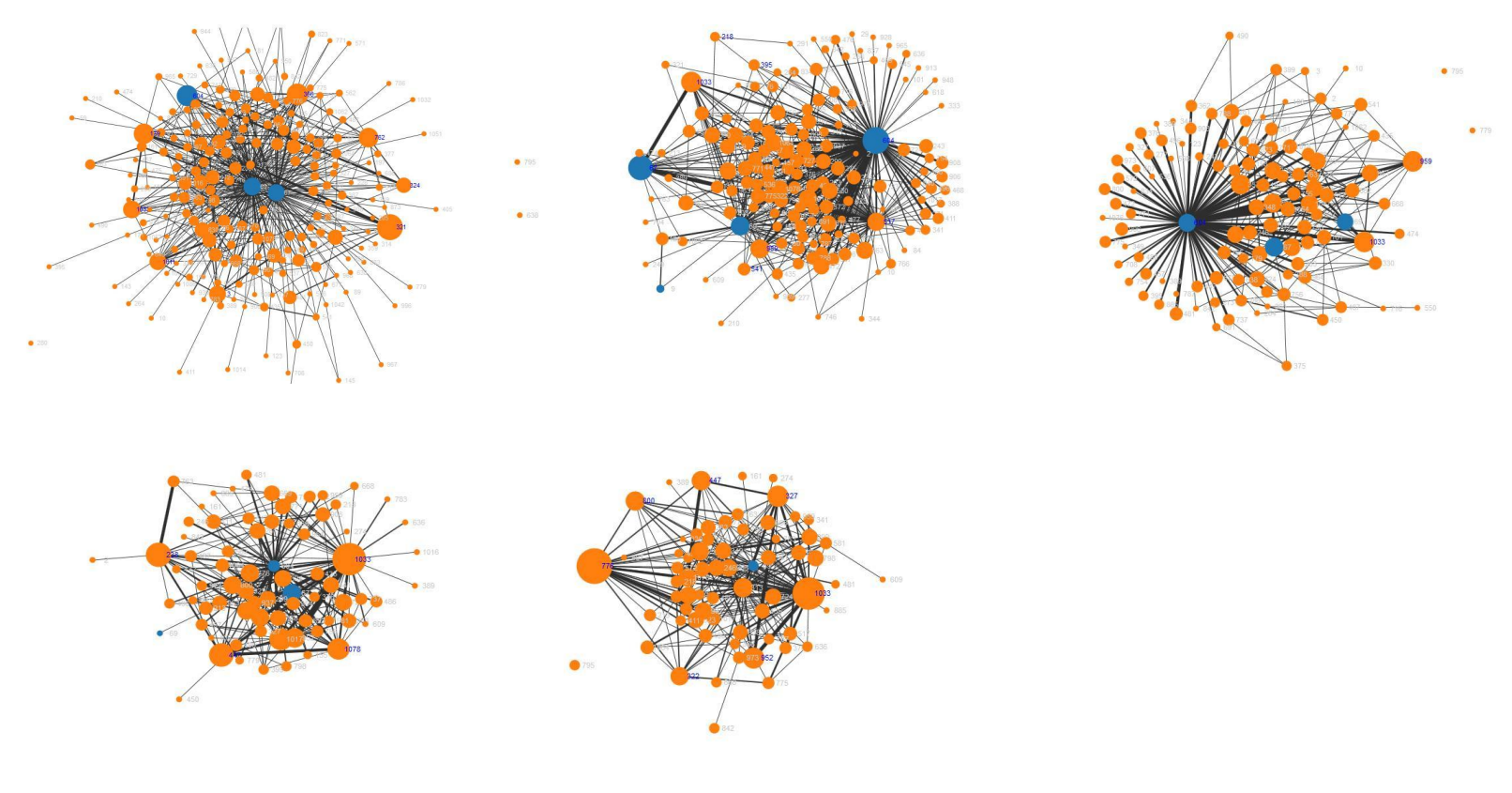

Note: Each dot ('node') represents an actor MOOC participants in orange, facilitators in blue), the size reflecting the number of messages sent. Lines ('edges') indicate the exchange of at least one message, the line thickness reflecting the number of messages exchanged. 
Table 2

Interactions in the weekly Moodle forums for the first edition of the HANDSON MOOC

\begin{tabular}{|l|r|r|r|r|r|}
\hline \multicolumn{1}{|c|}{ Course Phase } & Participants & \multicolumn{1}{c|}{$\begin{array}{c}\text { Discussion } \\
\text { Threads Created }\end{array}$} & $\begin{array}{c}\text { Total Number } \\
\text { Of Messages }\end{array}$ & $\begin{array}{c}\text { Av. Number Of } \\
\text { Participants Per } \\
\text { Thread }\end{array}$ & $\begin{array}{c}\text { Av. Number Of } \\
\text { Messages Per } \\
\text { Participant }\end{array}$ \\
\hline 1st week forum & 218 & 40 & 663 & 5.05 & 3.04 \\
\hline 2nd week forum & 152 & 11 & 656 & 13.8 & 4.31 \\
\hline 3rd week forum & 114 & 19 & 466 & 6.0 & 4.08 \\
\hline 4th week forum & 75 & 8 & 377 & 9.4 & 5.02 \\
\hline 5th week forum & 67 & 24 & 359 & 2.8 & 5.35 \\
\hline Total & 626 & 102 & 2521 & 6.2 & 4.02 \\
\hline
\end{tabular}

Despite the rather intense level of course activity, the interactions in the Moodle forums (which encompass any action, not just messaging) ceased once the MOOC finished (the course platform remained open after week 5, though). Figure 2 depicts the Moodle activity over time. It clearly shows how the activity peaked at the beginning of the MOOC (start date May 19), slowly fell off during the MOOC's runtime, and then - after the final week on June 20 - quickly fell back to no activity at all. The same pattern is repeated in the design environment (ILDE), as Figure 3 shows.

\section{Figure 2}

Activity report for the Moodle platform during the first edition of the HANDSON MOOC. Activities amount to any interaction with the platform.

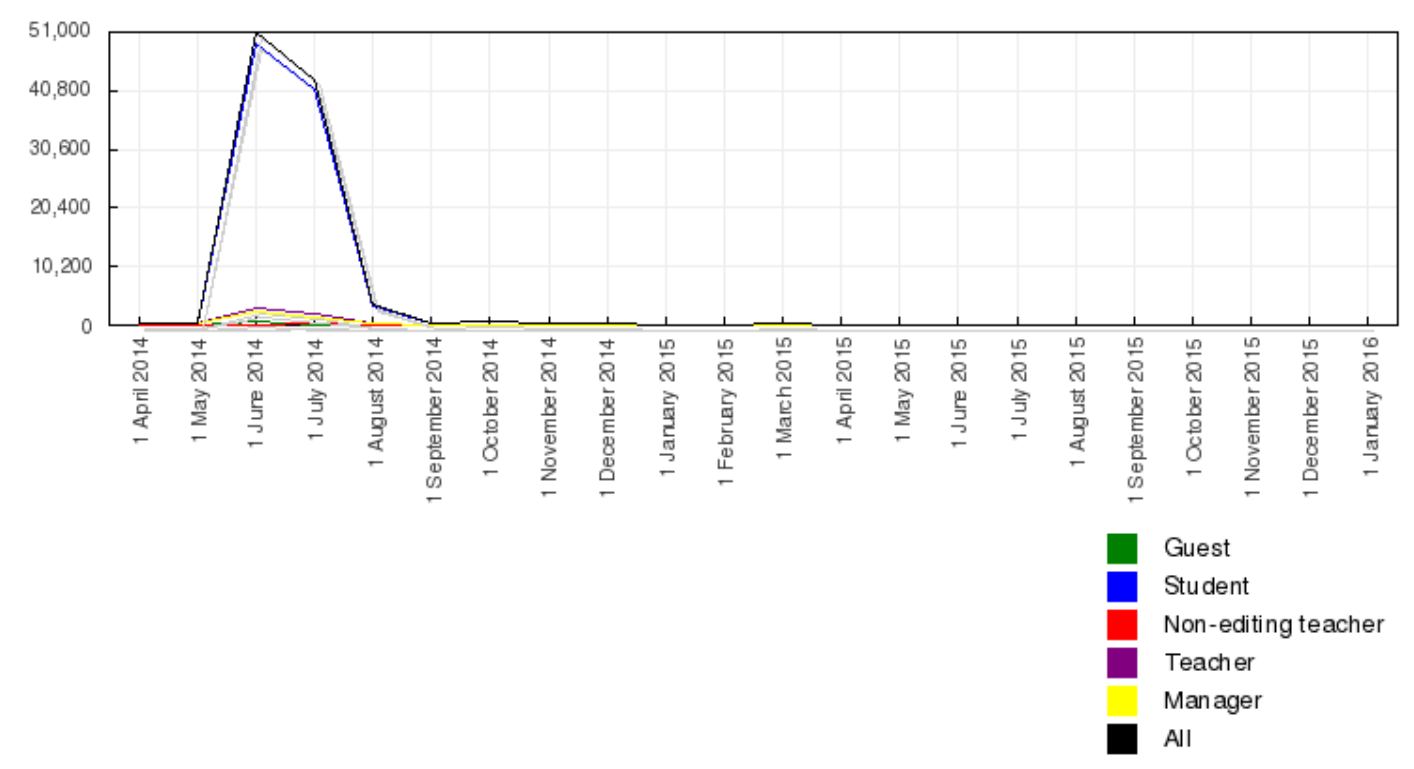


Figure 3

Time-stamped numbers of comments to learning designs in the ILDE environment for the first edition of the HANDSON MOOC

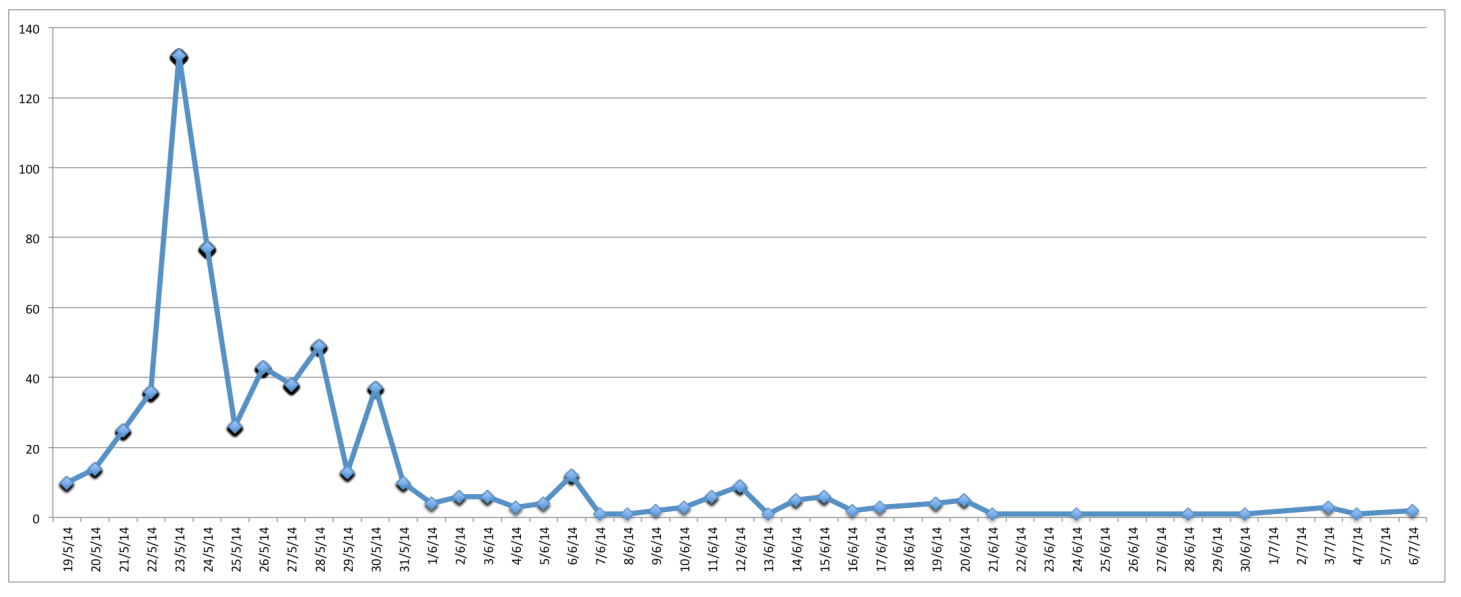

These data in Figures 2 and 3 from the Moodle and ILDE platforms respectively, are complemented by the data the participants themselves reported (Tables 3 and 4). The tables show survey responses related to the communicative and collaborative aspects of the MOOC. Table 3 shows participant responses to the pre-survey sent just before the start of the MOOC. Participants were asked to rate their agreement with four statements. Their answers reveal they felt collaboration and interaction with peers was less relevant (at $55.9 \%$ ) than with tutors and facilitators $(72.2 \%$ and $83.9 \%)$. This suggests that, at the start of the MOOC, participants did not so much intend to contribute to community formation (as Table 2 and Figure 1 suggest) but were individually seeking to increase their learning outcomes by connecting with facilitators. However, when asked specifically about community formation aspects after the course (Table 4), $76.7 \%$ agreed that a sense of community had arisen, with an average of $64.4 \%$ (of the entire group) agreeing about the usefulness of this.

Table 3

Responses to selected pre-survey questions for the first edition of the HANDSON MOOC

\begin{tabular}{|l|r|r|r|}
\hline \multicolumn{1}{|c|}{ Question } & \multicolumn{1}{c|}{ Agree } & \multicolumn{1}{c|}{ Undecided } & \multicolumn{1}{c|}{ Disagree } \\
\hline Interaction with other course participants & 55.9 & 27.7 & 16.4 \\
\hline Interaction with a facilitator/tutor & 72.2 & 21.2 & 6.5 \\
\hline $\begin{array}{l}\text { Facilitators/tutors feedback on } \\
\text { participants activity }\end{array}$ & 83.9 & 12.5 & 3.7 \\
\hline Collaborative work & 60.7 & 25.9 & 13.5 \\
\hline Average & 68.18 & 21.83 & 10.03 \\
\hline
\end{tabular}


Note: Responses in percentages; participants were asked to what extent they agreed with the statements given when attending an online course; total number of respondents to the survey 325.

Table 4

Responses to selected post-survey questions for the first edition of the HANDSON MOOC

\begin{tabular}{|l|r|r|r|}
\hline \multicolumn{1}{|c|}{ Question } & \multicolumn{1}{c|}{ Agree } & \multicolumn{1}{c|}{ Undecided } & \multicolumn{1}{c|}{ Disagree } \\
\hline The course provided a sense of community & 76.7 & 16.9 & 6.3 \\
\hline The course has promoted interaction with my peers & 67.6 & 26.1 & 6.3 \\
\hline The feedback I received from the course team was useful & 57.7 & 31.0 & 11.2 \\
\hline The feedback I received from my peers was useful & 55.6 & 28.2 & 16.2 \\
\hline Average & 64.40 & 25.55 & 10.00 \\
\hline
\end{tabular}

Note: Responses in percentages; participants were asked to what extent they agreed with the statements given when attending an online course; total number of respondents to the survey 142.

\section{Second edition}

As indicated in Table 1, in the second edition of the HANDSON MOOC participants could communicate with each other in any one of seven languages (Bulgarian, Catalan, English, Greek, Spanish, French, and Slovenian). Although the learning activities, the course materials and the general announcements remained in English only, the participants had to join any one of the seven language groups before they could actually follow the course. The rationale for this social design change was to facilitate and promote interaction among participants in order to create a sense of community. The assumption, based on positive experiences with an impromptu Greek-only group in the first edition, was that community formation is more likely to occur if one is able to speak one's native tongue or at least a language one is fluent in. With community formation, we intended to further increase the quality of the feedback that participants received from their peers (Colas et al. 2016; Garreta-Domingo et al. 2015a).

Unfortunately, the Canvas VLE used for this second edition did not allow us to make a social network analysis. However, as did Figure 3, Figure 4 shows the number of comments that peers made on the learning designs that MOOC participants created during the course. As in Figure 3, we see how the activity peaked at the beginning of the course. However, Figure 4 also shows much more variation in activity levels than did Figure 3. Presumably, the activity peaks and troughs are synchronised with the tasks the MOOC participants were required to carry out. Remember how for the second edition peermentoring tasks were an explicit part of the epistemic design. In the first edition, participants were invited but not obliged to comment ( $c f$. Table 1). This kind of synchronisation we spotted in the first edition as well, but there it only became apparent through the fluctuating numbers of discussion threads. 
Figure 4

Time-stamped numbers of comments to learning designs in the ILDE environment for the second edition of the HANDSON MOOC

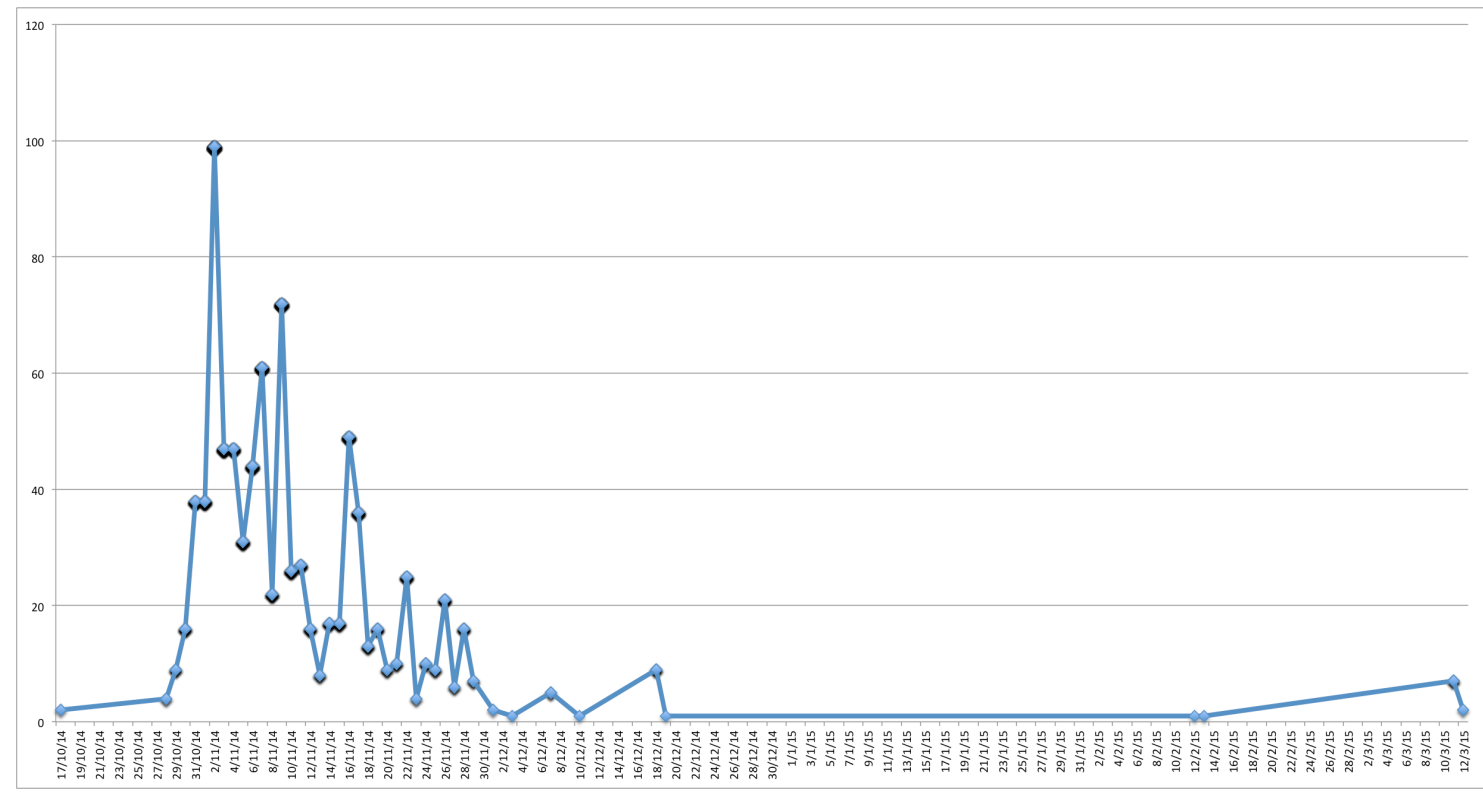

As in the first edition, pre and post MOOC surveys were sent out to participants (Tables 5 and 6). Here too, initially the course participants were not really interested in interacting and collaborating with each other as peers and expected to get more from their facilitators, despite the supposedly stronger feeling of community that a shared language supposedly brings (Table 5).

Table 5

Responses to selected pre-survey questions for the second edition of the HANDSON MOOC

\begin{tabular}{|l|r|r|r|}
\hline \multicolumn{1}{|c|}{ Question } & \multicolumn{1}{c|}{ Agree } & \multicolumn{1}{c|}{ Undecided } & \multicolumn{1}{c|}{ Disagree } \\
\hline Interaction with other course participants & 55.1 & 30.1 & 14.8 \\
\hline Interaction with a facilitator/tutor & 68.8 & 20.8 & 10.3 \\
\hline $\begin{array}{l}\text { Facilitators/tutors feedback on } \\
\text { participants activity }\end{array}$ & 73.8 & 17.7 & 8.4 \\
\hline Collaborative work & 54.0 & 28.8 & 17.1 \\
\hline Average & 62.93 & 24.35 & 12.65 \\
\hline
\end{tabular}


Note: Responses in percentages; participants were asked to what extent they agreed with the factors given when attending an online course; $27.4 \%$ respondents came from Spain, $14.3 \%$ from Greece and $13.7 \%$ from Bulgaria (totalling $55.4 \%$ of all respondents); total number of respondents to the survey 379 .

Table 6

Responses to selected post-survey questions for the second edition of the HANDSON MOOC

\begin{tabular}{|l|r|r|r|}
\hline \multicolumn{1}{|c|}{ Questions } & \multicolumn{1}{|c|}{ Agree } & \multicolumn{1}{c|}{ Undecided } & Disagree \\
\hline $\begin{array}{l}\text { The course provided a sense of } \\
\text { community }\end{array}$ & 74.4 & 15.9 & 9.7 \\
\hline $\begin{array}{l}\text { The course has promoted interaction } \\
\text { with my peers }\end{array}$ & 64.6 & 24.4 & 11.0 \\
\hline $\begin{array}{l}\text { The feedback I received from the } \\
\text { course team helped me with my } \\
\text { learning activities }\end{array}$ & 75.6 & 15.9 & 8.5 \\
\hline $\begin{array}{l}\text { The feedback I received from my } \\
\text { peers helped me with my learning } \\
\text { activities }\end{array}$ & 65.8 & 19.5 & 14.6 \\
\hline Average & 70.10 & 18.93 & 10.95 \\
\hline
\end{tabular}

Note: Responses in percentages; participants were asked to what extent they agreed with the factors given when attending an online course; $24.3 \%$ respondents came from Spain, $21.9 \%$ from Greece and $28.0 \%$ from Bulgaria (totalling $74.2 \%$ of all respondents); total number of respondents to the survey 82 .

But, as in the first edition, in due time participants arrived at the agreement that a sense of community had arisen (Table 6: $74.4 \%$, compare with $76.7 \%$ in Table 4). This is also reflected in their answers to the more specific question about the usefulness of peer and facilitator interaction (Table 6: average level of agreement $70.10 \%$, compared with $64.4 \%$ for the first edition - Table 4). As the increased percentage for the second edition is solely due to the higher appreciation of the feedback, it is likely this should be attributed to the fact that peer and facilitator interaction was conducted in each participant's own, preferred language; together with the added value from the rubrics for the mandatory peer-review activities (cf. Table 1). This is the more likely as the content expertise of the volunteer facilitators was lower than those of the paid facilitators. Thus, the many volunteer facilitators were less able to give feedback on the specifics of the course content and activities.

In an effort to learn about the fate of the language communities, six months after the ending of the HANDSON MOOC project, a short survey was sent out to the 15 volunteer facilitators for the second edition. The nine facilitators that responded confirmed that all activity in their language communities had ceased, with the exception of the Greek and English ones. We presume this is due to the fact that the 
entire Greek group of participants and part of the English group were recruited from existing online communities (Colas, Sloep and Garreta-Domingo 2016).

\section{In conclusion: Pop-up communities for the common good}

The data gathered from the first edition of the MOOC suggest that participants came to it with their individual aims and goals, as networked individualism would have it. However, over the course of the course, peer interaction increased while facilitator interaction decreased. Apparently, the participants appreciated this and confessed to having developed a sense of community, which they welcomed. The second edition confirms this picture. Again, participants were happy to tend to their own goals and interests only, nevertheless they appreciated the sense of community that developed over time. The fact that they received feedback in their own language, did not affect this sense of community (in either direction).

The development and appreciation of a sense of community seems to fly in the face of what networked individualism holds. It also mitigates the pessimistic scenario that Robert Putnam paints, at least for this miniature universum of MOOC-based networked learning. We assume that our observations describe a genuine phenomenon, as it is in line with observations of other learning theorists (e.g. Dron and Anderson 2014; Illeris 2007). The question then is what caused the participants to change their opinion, what is the mechanism behind this change?

We suggest that the social dynamics of such networks is driven by a special kind of community, which we call pop-up communities. They are unlike traditional communities, which usually do not aim to achieve a specific goal and typically are tightly knit and long lasting. Examples of such 'ordinary' communities are geographical communities as in villages and neighbourhoods, but also the communities of practice that emerge in and across companies (Brown and Duguid 2000; Wenger 1998). In contrast, pop-up communities are characterised by their purposefulness - they emerge for a specific purpose only, and their temporariness - they disappear once they've outlived that purpose. Although they are tightly knit during their existence, the weak bonds that have been established typically do not last long enough to become strong ones. We suggest that the communities that arose in the HANDSON MOOC discussed, particularly the language-specific ones from the second edition, are such pop-up communities. It is because participants establish a link with each other, even if ever so briefly, that they can pursue their common goal, be it clarifying an issue, answering a question or completing a task. Note, how such communities fit the tenets of networked individualism. With appropriate mechanisms in place - simple searching, recommender systems, matching algorithms - network participants can 'meet' easily, without necessarily investing much in the transaction costs of setting up such meetings. And just as easily they may leave the community to go on with their own business and perhaps join another pop-up community with serves their then needs. Note also how this description of the network participants' behaviour fits the expectations they themselves confess to have.

In the past, others have stumbled upon similar findings. Thus, in 2002 already Bonnie Nardi and colleagues described intensional networks in the context of computer-supported collaborative work (Nardi, Whittaker and Schwarz 2002). Such networks take personal social networks as building blocks rather than top-down created teams. Then, in relation to open source software development, Steven Weber discusses episodic communities on demand: "virtual organizations that come together 
frictionlessly for a particular task and then redistribute to the next task just as smoothly" (Weber 2004, p. 171). Sloep (2009) introduces the notion of ad-hoc transient communities to denote small groups of students, one of whom asks a question that the others answer in a collective, dedicated, online discussion space (see also Van Rosmalen et al. 2008).

It is our view that such short-lived communities that dedicate themselves to a simple goal exemplify networked individualism. However, their effect is not necessarily disruptive, as Putnam describes. Any pop-up community not only captures the collective intelligence of its participants, it also provides an opportunity for building on this collective intelligence and let it work for the common good. The weak links established in a pop-up community may grow into strong ones if the participants want to (see also Haythornthwaite 2002). The data collected show evidence for this: participants become less focused on peer-tutor interactions and more on peer-peer interactions. Also, they confess to appreciating this shift in social communication patterns from one that is characteristic for education (peer to teacher/tutor) to one that is characteristic of equitable social relationships (peer to peer). Admittedly, the data also reveal that, given the short duration of the experience of several weeks, the peer-to-peer relationships did not last in the majority of the language communities. However, the fact that they did in the language communities that had a previous history, bodes well for our claim that pop-up communities may breed a sense of community that stimulates people to keep collaborating and thus contribute to their common good. We may live in an age of networked individualism, as Lee Rainie and Barry Wellman claim (2012). However, this does not imply people would be unwilling to contribute to the common good. It only takes a different form and the mechanism through which such contributions come about is different. This paper suggests that pop-up communities are such a mechanism.

Ours is a specific case in the realm of education and, more specifically, in networked learning for inservice educators. It is a contribution to the galaxy of initiatives working towards the same purpose: harnessing the collective intelligence of networks. The Statement of Principles of the Public Sphere Project (www.publicsphereproject.org) also addresses directly the aim of promoting the common good that networked individualism is threatening. These instances of collective intelligence can happen offline, online and/or with the combination of both as is discussed by Mark Bilandzic and Marcus Foth (2016). Looking further away in the galaxy, we find projects aligned in another dimension: long-term versus. short-term. Joel Fredericks et al. (2015) studied the effect of a digital device deployed with a pop-up style format for the purpose of community engagement; whereas Hillary Cottam, from the participatory design perspective, has worked in projects to redefine public services (www.participle.net/ageing). She shows that through the creation of 'Circles' of people living close to each other, the demand for public services is diminished while a better; more personal and timely service is obtained. Through these different initiatives we can grasp two current characteristics of the routes for collective intelligence for the common good: they are wide in approach and scope; they are scattered and experimental. It is up to us to create the map that through convergence and intertwining can facilitate the much needed growth and strength.

\section{Acknowledgement}

We want to thank all facilitators for voluntarily donating their precious time to the HANDSON project, and to the HANDSON team as a whole for their productive collaboration. See the project website for details on the project and its participants: http://handsonict.eu/. 
The HANDSON project (531086-LLP-1-2012-1-ES-KA3-KA3MP) has been funded with support from the Lifelong Learning Programme of the European Commission.

\section{References}

Bates T (2015) Teaching in a Digital Age. University of British Columbia, Vancouver

Bilandzic M, Foth M (2016) Designing Hubs for Connected Learning - Social, Spatial and Technological Insights from Coworking, Hackerspaces and Meetup Groups. In: Carvalho L, Goodyear P, De Laat M (eds.), Place-based spaces for networked learning. Routledge, London

Brown J S Duguid P (2000) The Social Life of Information. Harvard Business School Press, Boston

Carvalho L, Goodyear P M (2014) The Architecture of Productive Learning Networks. Routledge Falmer, New York, London

Colas J-F, Sloep PB, Garreta-Domingo M (2016) The effect of multilingual facilitation on active participation in MOOCs. International Review of Research in Open and Distance Learning 17(4):280-314

Dalziel J (2016) Learning Design: Conceptualizing a Framework for Teaching and Learning Online. Routledge Taylor \& Francis Group, New York and London

Daniel J (2012) Making Sense of MOOCs: Musings in a Maze of Myth, Paradox and Possibility. Journal of Interactive Media in Education 18:1-19

Dillenbourg P (1999) Collaborative Learning: Cognitive and Computational Approaches. Advances in Learning and Instruction Series. Elsevier Science, New York

Dron J, Anderson T (2014) Teaching Crowds; Learning and Social Media. AU Press, Athabasca, Canada

Fredericks J, Tomitsch M, Hespanhol L, McArthur I (2015) Digital Pop-Up. In: Proceedings of the Annual Meeting of the Australian Special Interest Group for Computer Human Interaction on OzCHI '15, pp 634-642

Garreta-Domingo M, Aguado Roman G, Mor Y, Fernandez C, Riviou K (2015). A Peer-Mentoring Approach for the Continuous Professional Development of Educators in a MOOC Setting. In: Eden Annual Conference 2015 Expanding Learning Scenarios. Barcelona

Garreta-Domingo M, Colas J-F (2015) Palm Reading of the HANDSON MOOC. Barcelona

Garreta-Domingo M, Hernández-Leo D, Mor Y, Sloep PB (2015) Teachers' Perceptions About the HANDSON MOOC: A Learning Design Studio Case. In: Conole G, Rensing C, Konert J, Hutchison D (eds) Design for Teaching and Learning in a Networked World; Proceedings of the 10th European Conference on Technology Enhanced Learning, EC-TEL 2015 Toledo, Spain, September 15-18, 2015 Proceedings. Springer, Berlin and Heidelberg, pp 420-427

Goodyear P M, Carvalho L (2014) Framing the analysis of learning network architectures. In: Carvalho L, Goodyear PM (eds) The Architecture of Productive Learning Networks. Routledge Falmer, New York and London, pp 48-70

Haythornthwaite C (2002) Strong, Weak, and Latent Ties and the Impact of New Media. The Information Society 18(5):385-401

Haythornthwaite C (2011) Learning Networks, Crowds and Communities. In: Proceedings of the 1st International Conference on Learning Analytics and Knowledge, LAK'11. ACM, New York, pp 1822

Hernández-Leo D, Asensio-Pérez JI, Derntl M, Prieto LP, Chacón J (2014) ILDE: community environment for conceptualizing, authoring and deploying learning activities. In: De Freitas S, Rensing C, Ley T, Muñoz-Merino PJ (eds), EC-TEL 2014 LNCS vol. 8719. Springer, Heidelberg, pp 490-493

Illeris K (2007) How we learn; Learning and non-learning in school and beyond (English ed). Routledge, Abingdon Oxon UK

Ilon L (2012) How collective intelligence redefines education. In Advances in Collective Intelligence. Springer, Berlin Heidelberg, pp 91-102 
Laurillard D (2012) Teaching as a Design Science: Building Pedagogical Patterns for Learning and Technology. Routledge, New York and London

Mor Y, Mogilevsky O (2013) The learning design studio: collaborative design inquiry as teachers' professional development. Research in Learning Technology, 21(1):1-15

Nardi BA, Whittaker S, Schwarz H (2002) NetWORKers and their activity in intensional networks. Computer Supported Cooperative Work 11(1-2):205-242

O'Hallarn B (2016) The public sphere and social capital: Unlikely allies in social media interactions? First Monday 21(10)

OECD (2015) Students, Computers and Learning; making the connection. OECD Press, Paris

Putnam RD (2000) Bowling Alone: The Collapse and Revival of American Community. Simon \& Schuster, New York

Rainie L, Wellman B (2012) Networked: The New Social Operating System. MIT Press, Cambridge, MA

Siemens G, Conole G (2011) Special Issue - Connectivism: Design and Delivery of Social Networked Learning. IRRODL 12(3)

Sloep PB (2009) Fostering Sociability in Learning Networks through Ad-Hoc Transient Communities. In: Purvis M, Savarimuthu BTR (eds) Computer-Mediated Social Networking ICCMSN 2008 LNAI 5322. Springer, Berlin Heidelberg, pp 62-75

Sloep PB, Berlanga AJ (2011) Learning Networks, Networked Learning [Redes de Aprendizaje, Aprendizaje en Red]. Comunicar XIX(37):55-63

Stoyanov S, Sloep PB, De Bie M, Hermans V (2014) Teacher-training, ICT, Creativity, MOOC, Moodle What pedagogy? In: Gómez Chova L, López Martínez A, Candel Torres I (eds) Proceedings of Edulearn 14 the Sixth International Conference on Education and New Learning Technologies. IATED Digital Library, Barcelona, pp 5678-5686

Van Rosmalen P, Sloep PB, Brouns F, Kester L, Berlanga AJ, Bitter-Rijpkema ME, Koper R (2008) A model for online learner support based on selecting appropriate peer tutors. Journal of Computer Assisted Learning, 24(6):483-493

Weber S (2004) The Success of Open Source. Harvard University Press, Cambridge MA

Wenger E (1998) Communities of Practice: Learning, Meaning, and Identity. Cambridge Univ Press Cambridge 